\section{Etiopatogênese Molecular dos Tumores Corticotróficos}

\begin{abstract}
RESUMO
Os corticotrofinomas representam aproximadamente $80 \%$ dos casos de síndrome de Cushing de origem endógena em adultos. Na última década, foram feitos avanços consideráveis na compreensão do desenvolvimento da hipófise anterior, na patogênese dos tumores hipofisários e nos fatores envolvidos na progressão tumoral. A aplicação do conceito geral de tumorigênese é adequada aos tumores corticotróficos, sendo este um processo que envolve várias etapas, resultantes da interação de eventos iniciadores e subseqüentemente de fatores promotores, sendo portanto multifatorial. De modo geral, oncogenes e genes de supressão tumoral freqüentemente relacionados a outros tipos de tumores não parecem contribuir neste processo, embora alteração na expressão de alguns destes genes, como p53, p16 e PTTG, possa estar relacionada a um comportamento fenotípico mais agressivo. A investigação das vias regulatórias específicas dos corticotrofos, principalmente a estrutura e a expressão dos genes dos receptores do $\mathrm{CRH}, \mathrm{AVP}$ e GR também não evidenciou a presença de mutações. Entretanto, é possível que alterações em regiões promotoras ou em co-fatores que regulam estes genes possam estar presentes. Estudos futuros sobres os mecanismos de regulação da célula corticotrófica normal e tumoral deverão contribuir na definição de marcadores prognósticos e no desenvolvimento de novas modalidades de tratamento. (Arq Bras Endocrinol Metab 2002;46/4:361-371)
\end{abstract}

Descritores: Doença de Cushing; Corticotrofinomas; Etiopatogênese; Genes; Genética

\begin{abstract}
Molecular Etiopathogenesis of Corticotrophic Tumors.

Corticotropinomas represent approximately $80 \%$ of the etiology of Cushing's syndrome in adults. In the past decade remarkable advances in the knowledge of the normal anterior pituitary development, in the pathogenesis of the pituitary tumors, as well as in the factors involved in the tumoral progression have been made. General principles of tumorigenesis are valid in corticotrophic tumors and it is clear that this is a multistep and multifactorial process, resulting from the interaction of initiating and promoting events. Most of the oncogenes and tumor suppressor genes related to other tumor types do not seem to contribute in this process, although abnormal expression of some of these genes, like PTTG, p53 and p16 can be related to a more aggressive phenotypic behavior. Investigation of the corticotrophicspecific regulatory pathways, mainly the structure and expression of the $\mathrm{CRH}, \mathrm{AVP}$, and GR receptor genes has also not shown significant abnormalities. However, it is possible that disruption in regulatory regions of these genes or in their transcription factors could be involved. Future studies in the regulatory mechanisms of both normal and tumoral corticotrophic cells could contribute in defining better
\end{abstract}

atualização

\author{
Sonir R. Antonini \\ Margaret de Castro
}

Disciplina de Endocrinologia Pediátrica (SRA), Departamento de Puericultura e Pediatria; $e$ Disciplina de Endocrinologia (MC), Departamento de Clínica Médica, Faculdade de Medicina de Ribeirãa Preto - USP, Ribeirão Preto, SP. 
prognostic markers and eventually in the development of new therapeutic strategie (Arq Bras Endocrinol Metab 2002;46/4:361-371)

Keywords: Cushing's disease; Corticotropinomas; Pathogenesis; Genes; Genetics

A SÍNDROME DE CUSHING (SC) é caracterizada por sinais e sintomas resultantes da exposição prolongada de todos os tecidos do organismo a altas concentrações de glicocorticóides (GC). Os tumores da hipófise anterior secretores de hormônio adrenocorticotrófico (ACTH), chamados de corticotrofinomas, são, na grande maioria dos casos, adenomas. Os corticotrofinomas representam cerca de $80 \%$ da etiologia dos casos de síndrome de Cushing de origem endógena em adultos (1). Na última década foram feitos avanços consideráveis no conhecimento do desenvolvimento da hipófise anterior, na patogênese dos tumores hipofisários, bem como nos fatores envolvidos na progressão tumoral. A caracterização da origem monoclonal dos tumores corticotróficos representou um marco importante na investigação da etiopatogenia desta doença (2). O papel de múltiplos genes envolvidos no desenvolvimento normal da hipófise anterior, na função hipofisária pós-natal e seu possível envolvimento no desenvolvimento tumoral está em constante investigação. A aplicação dos conceitos gerais de tumorigênese é adequada para os corticotrofinomas, isto é, o processo de formação tumoral envolve várias etapas resultantes da interação de evento(s) iniciadore(s) e, subseqüentemente, de fatores promotores do crescimento do clone tumoral. Em alguns tipos de tumores hipofisários, várias alterações gênicas têm sido descritas, entretanto no caso específico dos corticotrofinomas, perda de atividade dos genes de supressão tumoral $\mathrm{e} /$ ou ganho de atividades de proto-oncogenes, freqüentemente relacionados a outros tipos de tumores, não estão comumente envolvidos na sua patogênese.

\section{ONTOGENIA DAS CÉLULAS CORTICOTRÓFICAS}

O desenvolvimento hipofisário ocorre de forma seqüencial e organizada e é controlado por uma série de moléculas sinalizadoras codificadas por genes de desenvolvimento, que atuam como importantes fatores de transcrição. Muitos desses genes são os chamados genes homeobox, cujas proteínas contém uma região de ligação ao DNA ou homeobox, que, em geral, apresenta elevada homologia estrutural entre diferentes espécies. Estes genes são expressos em fases distintas e específicas da embriogênese hipofisária.
Alguns têm sua expressão restrita a um período determinado, enquanto outros continuam a ser expressos durante toda a vida pós-natal, sendo fundamentais para a função da célula corticotrófica (3).

A hipófise anterior desenvolve-se a partir da bolsa de Rathke na primitiva cavidade oral e migra cranialmente, enquanto que a hipófise posterior origina-se a partir do diencéfalo ventral, migrando caudalmente. Parece haver uma espécie de tropismo positivo entre estas duas estruturas embrionárias e sua interação é imprescindível para que ocorra perfeita diferenciação celular (3). A partir de uma linhagem celular pouco diferenciada de origem ectodérmica ocorre proliferação e diferenciação em 5 diferentes linhagens celulares, que secretam pró-opiomelanocortina (POMC), hormônio de crescimento $(\mathrm{GH})$, prolactina (PRL), hormônio estimulador da tireóide (TSH), hormônio luteinizante (LH) e hormônio folículo-estimulante (FSH) (figura 1). À medida que essas linhagens celulares vão se diferenciando, peptídeos hipotalâmicos começam a exercer controle neste processo. O gene Hesxl (RPX) tem sua expressão limitada ao período inicial do desenvolvimento hipofisário e parece ser fundamental na diferenciação de todas as linhagens celulares. Experimentos de knock-out em camundongos, além de mutações levando a pan-hipopituitarismo na espécie humana, comprovam esta hipótese (4). O gene codificador da subunidade $\alpha$-glicoprotéica $(\alpha-G S U)$, componente fundamental do TSH, LH e FSH, também se torna ativo precocemente. O gene Ptxl é um dos primeiros a serem expressos e parece exercer um importante papel na diferenciação celular e na formação da própria glândula, sendo expresso em todas as células. Entretanto, sua expressão persiste na vida adulta, nas linhagens celulares secretoras de POMC, TSH e LH/FSH, parecendo atuar, independentemente, na transcrição dos

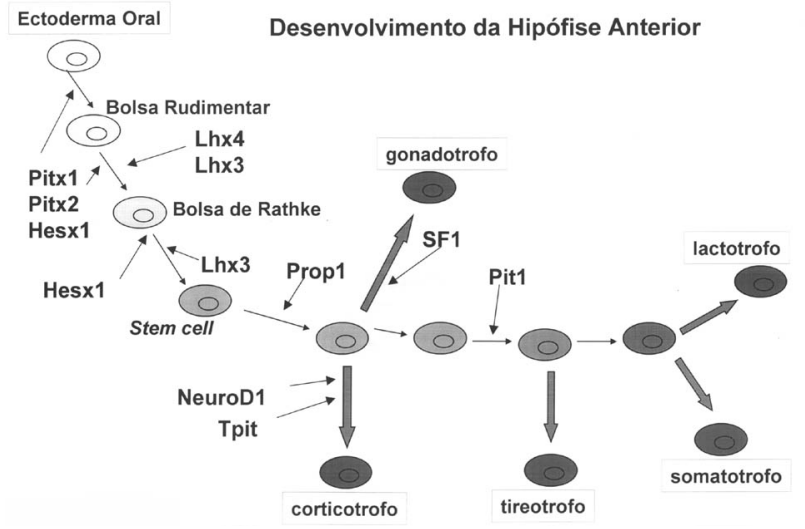

Figura 1. Genes envolvidos no desenvolvimento seqüencial das 5 linhagens celulares da hipófise anterior.

Arq Bras Endocrinol Metab vol 46 n 4 Agosto 2002 
genes POMC e da $\alpha$-GSU (5). O gene Pit-1 inicialmente é expresso em todas as células, na vida adulta; entretanto, só é detectado em 3 linhagens celulares. Mutações deste gene levam a hipopituitarismo parcial, com deficiência de GH, TSH e PRL (6). Os genes $L h x 3$ e $L h x 4$ (ou $P$-Lim) atuam na transcrição da $\alpha$ GSU e parecem co-operar com o Pit-I na ativação de outros genes (7). A expressão do gene Prop-l é fundamental para a posterior, específica e permanente expressão do gene Pit-I nos somatotrofos, galactotrofos e tireotrofos. Prop-I também é importante na diferenciação dos corticotrofos, visto que indivíduos com mutações neste gene podem apresentar também deficiência de ACTH (8). O leukemia inbibitory factor (LIF) é expresso durante o desenvolvimento das células corticotróficas e atua em sinergismo com o CRH, aumentando a expressão da POMC. Entretanto, LIF também exerce efeito antiproliferativo sobre os corticotrofos (9). Recentemente foi isolado um novo fator de transcrição, Tpit, que, agindo em cooperação com Ptxl, parece ser fundamental na diferenciação dos corticotrofos, bem como na ativação do gene POMC. Mutações no gene Tpit causam deficiência isolada de ACTH (10). Até o momento, não existem indícios do envolvimento de genes de desenvolvimento na tumorigênese hipofisária (11).

\section{TUMORIGÊNESE HIPOFISÁRIA}

Os tumores hipofisários apresentam, em sua grande maioria, comportamento benigno, embora Sautner e Saeger (12), examinando um grande número de tumores, tenham encontrado algum grau de invasão local em $42 \%$ deles. Os adenomas hipofisários, de modo geral, são muito mais freqüentes no sexo feminino e os corticotrofinomas são cerca de quatro vezes mais freqüentes em mulheres. A explicação fisiopatológica para esta maior prevalência no sexo feminino não é totalmente conhecida, entretanto, os estrógenos parecem desempenhar papel importante. In vitro, o estrogênio é capaz de estimular fatores de crescimento em linhagens de células hipofisárias (13). Não existem evidências in vivo de uma influência direta dos estrógenos na tumorigênese; entretanto, recentemente foi descrita a ação angiogênica dos estrógenos em tecidos hipofisários, através da estimulação de fatores de crescimento, como o fator de crescimento fibroblástico (FGF) (14). Existe uma alta prevalência (11-23\%) de adenomas hipofisários "ocultos", encontrados em séries de autópsias, contrastando com a baixa ocorrência clínica desses tumores que varia de 0,02 a $0,025 \%$, na população geral (15). Os tumores hipofisários apresentam um tempo de duplicação de 100 a 700 dias e cerca de $70 \%$ dos tumores hipofisários são diagnosticados em indivíduos com 30 a 50 anos de idade (16). Tumores hipofisários que apresentam uma taxa de crescimento acelerada podem ser encontrados em indivíduos com idade inferior a 20 anos, como os corticotrofinomas e os somatotrofinomas que ocorrem em crianças ou adolescentes.

A origem dos tumores hipofisários e dos corticotrofinomas em particular, se hipotalâmica ou hipofisária, foi objeto de grande discussão no passado. Sugeriu-se que a exposição crônica dos corticotrófos a concentrações elevadas dos fatores estimulatórios hipotalâmicos poderia levar ao desenvolvimento dos adenomas (17). Entretanto, evidências como a total remissão dos sintomas após a remoção cirúrgica e a inexistência de hiperplasia nas áreas adjacentes ao tumor, tornaram esta hipótese pouco provável. A comprovação definitiva do caráter monoclonal desses tumores $(2,19)$, demonstra claramente que o hipotálamo não tem participação na iniciação do processo de tumorigênese hipofisária e é compatível com a hipótese de que alterações somáticas precedem a expansão clonal de uma célula corticotrófica modificada (figura 2). É possível que, nos raros casos onde foi demonstrada a policlonalidade tumoral, tenha havido contaminação das amostras estudadas com células nãotumorais adjacentes $(2,20)$. Em alguns raros casos, o caráter monoclonal pode ser adquirido num período posterior a um crescimento policlonal (2).

O processo de tumorigênese hipofisária é, geralmente, desencadeado por um evento iniciador, como uma mutação espontânea ou adquirida e, subseqüentemente, por eventos promotores que permitem a expansão do clone tumoral. Esta expansão pode ser sustentada por fatores tróficos, intrínsecos ou extrínsecos (2l). As alterações moleculares que levam ao desenvolvimento destes tumores são apenas parcialmente conhecidas. Dentre os múltiplos eventos que

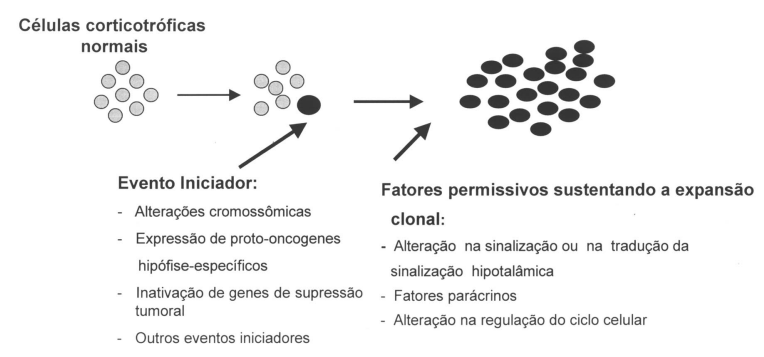

Figura 2. Tumorigênese hipofisária: ação de um evento iniciador e posteriormente de fator(es) permissivo(s), favorecendo a expansão do clone tumoral. 


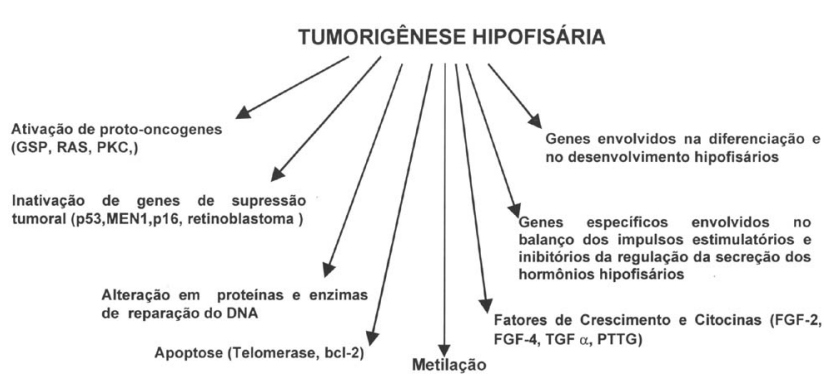

Figura 3. Genes e fatores candidatos na etiopatogênese dos tumores hipofisários.

podem contribuir para iniciação da patogênese dos adenomas hipofisários estão as alterações cromossômicas e a expressão de protooncogenes específicos da hipófise. Fatores permissivos subseqüentes permitiriam a expansão clonal da célula hipofisária transformada e podem incluir sinais traduzidos pelos receptores dos hormônios hipotalâmicos, pelos fatores de crescimento parácrinos e por alterações na sinalização da regulação do ciclo celular (figura 3). Esta cascata de eventos resulta em: proliferação celular, transcrição gênica e secreção hormonal desenfreada, que são a marca registrada desses tumores (11).

\section{ONCOGENES}

Um oncogene resulta de mutação em um proto-oncogene, com "ganho de função", levando à formação de uma proteína aberrante. Tipicamente, é necessário que apenas um alelo seja afetado para que ocorra este ganho de função. Mutações somáticas em oncogenes envolvidos na proliferação celular e na secreção hormonal têm sido relatadas em adenomas hipofisários. Mutações nos genes que codificam as diversas subunidades do complexo ligado à proteína $\mathrm{G}$ não parecem estar envolvidas na patogênese dos corticotrofinomas (22), ao contrário dos somatotrofinomas onde mutações no oncogene GSP têm sido identificadas em cerca de $40 \%$ dos casos, em populações ocidentais $(21,23,24)$. Mutações no oncogene RAS foram encontradas em alguns prolactinomas de comportamento muito agressivo (25), assim como mutações nos genes da proteína quinase $\mathrm{C}(P K C), c-M Y C$ e $c^{-}$ $E R B 2 / n e u$ também foram encontradas em tumores de comportamento muito invasivo, mas não em adenomas corticotróficos (26-28).

Recentemente, um novo fator de crescimento, o pituitary tumor-transforming gene (PTTG), foi isolado em somatotrofinomas e alguns outros adenomas funcionantes, incluindo 1 corticotrofinoma. Esta proteína não é expressa em tecidos hipofisários normais, demons- trando, portanto, a presença de um gene transformador específico nestes adenomas $(29,30)$. O PTTG age através do fator de crescimento dos fibroblastos (FGF) e parece estar envolvido no processo de angiogênese tumoral, um importante mecanismo mediando a tumorigênese hipofisária (31). Portanto, estudos futuros são necessários para demonstrar a importância deste gene na proliferação das células tumorais.

\section{GENES DE SUPRESSÃO TUMORAL}

Genes de supressão tumoral normalmente codificam proteínas que regulam o ciclo celular e mantém a estabilidade genômica. Mutações que comprometem sua função podem levar à formação de um tumor. De maneira geral, é necessário que ambos os alelos sejam afetados para que ocorra esta "perda de função". Mutação no gene de supressão tumoral $p 53$ parece ser a alteração gênica mais freqüente em neoplasias na espécie humana, estando associada a aproximadamente $50 \%$ de todos os tipos de câncer (21). Os estudos do gene p53 em tumores hipofisários têm demonstrado resultados contraditórios. Alguns grupos têm demonstrado ausência de mutações na região hotspot desse gene, em adenomas (32) e em carcinomas hipofisários (33). Entretanto, Buckley e cols. (34) demonstraram expressão aumentada da proteína p53 em corticotrofinomas e em tumores hipofisários não-funcionantes de comportamento invasivo. Estudo posterior demonstrou que, dependendo do anticorpo usado, existe uma variação significativa na quantidade da proteína p53 detectada, bem como em relação à sua localização nuclear ou citoplasmática (35). O acúmulo citoplasmático da proteína p53 parece ser devido à formação de complexo com a proteína de choque 70 (hsp70), entretanto, na subpopulação de tumores em que há um acúmulo real da proteína p53 no núcleo celular, existem evidências de uma menor capacidade de apoptose. Deste modo, a função apoptótica da proteína p53 encontra-se reduzida em parte dos tumores corticotróficos (35). O papel de genes relacionados ao gene $p 53$, como os genes $p 73$ e $p 33$, entre outros recentemente clonados, na tumorigênese corticotrófica ainda não foi devidamente explorado (36-39).

Mutações no gene MENI (locus 1lq13) estão relacionadas à neoplasia endócrina múltipla tipo 1 . Estudando uma série de tumores hipofisários, McCabe e cols. (40) demonstraram que mutações na região codificadora do gene $M E N I$ são incomuns nos adenomas não-funcionantes, nos adenomas produtores de TSH e nos produtores de GH, entretanto, 
perda de heterozigose ( $\mathrm{LOH}$ ) neste locus foi encontrada em alguns tumores hipofisários não-funcionantes, bem como em carcinomas corticotróficos (41). No único corticotrofinoma estudado na série de McCabe e cols. (40) também não foram encontradas alterações no locus $1 \mathrm{lql} 3$. Entretanto, na maioria destes tumores, a expressão pré-tradução deste gene estava aumentada. O significado destes achados permanece sob investigação.

Recentemente, estudando um outro gene de supressão tumoral, o gene $p 27 / k i p 1 / C D K N 4$, em tumores hipofisários secretores de ACTH, Dahia e cols. (42) não encontraram mutações ou alteração na expressão deste gene. A expressão de um outro importante gene envolvido diretamente no controle do ciclo celular, o gene $p 16 / C D K N 2 / M T S 1 / I N K 4$, encontrase diminuída nos tumores hipofisários e esta diminuição é devida a um estado de hipermetilação na região promotora deste gene (43). Apesar de não haverem sido identificadas mutações no gene pl6, $\mathrm{LOH}$ no locus 9p21 foi encontrada em tumores hipofisários, demonstrando que outro gene desta região pode estar envolvido (44).

LOH no locus RBI (13q14) tem sido demonstrada em tumores hipofisários de comportamento agressivo, entretanto, mutações no gene $R B 1$ não foram encontradas nestes casos, sugerindo a existência de outro gene de supressão tumoral nesta região (27). Outros genes de supressão tumoral, como, por exemplo, os genes $N M 23$ e $B R C A 2$, não parecem estar envolvidos na tumorigênese corticotrófica (45). LOH nos loci lp, 3p, 10q26, 1lq13 e 22ql2 tem sido descrita em alguns carcinomas corticotróficos (46).

\section{FATORES DE CRESCIMENTO E CITOCINAS}

O envolvimento de fatores de crescimento no processo de tumorigênese tem sido bastante estudado. Entre os possíveis fatores de crescimento e citocinas envolvidos estão a interleucina 6 (IL-6), FGF-2 e FGF-4 $(28,47)$. O FGF-2 normalmente não é expresso em tecidos hipofisários normais; entretanto, sua expressão tem sido detectada em tumores somato-lactotróficos (28). Estudos de transfecção, em linhagens celulares derivadas destes tumores, têm demonstrado que quanto maior a expressão deste gene, mais agressivo parece ser o comportamento do tumor (48). O FGF é ativado pelo PTTG e possui ação angiogênica potente, estando provavelmente envolvido na progressão tumoral (49), incluindo os tumores hipofisários (50). Alterações no gene codificador do transforming growth factor (TGF) têm sido encontradas principalmente em prolactinomas, mas não em corticotrofinomas (2l).

LIF, membro da família das citocinas, que atua através de receptor próprio, o LIF-R, está envolvido na diferenciação e também no funcionamento da célula corticotrófica normal (vide secção II). O papel do LIF e do LIF-R na tumorigênese hipofisária tem sido investigado, principalmente através de linhagens transgênicas superexpressando LIF. Entretanto, os resultados têm sido controversos, tendo sido encontrada diminuição da atividade do gene $\operatorname{POMC}$ (51) ou hiperplasia corticotrófica (52).

\section{SINALIZAÇÃO DOS GENES REGULADORES}

A secreção de ACTH é controlada principalmente pela transcrição do gene da POMC e do hormônio liberador da corticotrofina $(\mathrm{CRH})$, sendo a transcrição destes genes regulada principalmente pelos GCs $(53,54)$. A ação inibitória dos GCs sobre o gene da $P O M C$ ocorre pela sua interação com elementos negativos responsivos aos GCs (nGRE), localizados na região promotora do gene da POMC (55). Mutações nesta região não foram encontradas em corticotrofinomas (56).

Alteração na tradução da sinalização dos hormônios hipotalâmicos representa outro possível mecanismo envolvido na iniciação ou na progressão do processo de tumorigênese corticotrófica (17). Os dois principais hormônios hipotalâmicos estimuladores das células corticotróficas são o hormônio liberador de corticotrofina (CRH) e a vasopressina (AVP).

$\mathrm{O} C R H$ age através da ligação ao seu receptor (CRH-R), portanto, mutações e/ou alteração na expressão do gene do CRH-R poderiam estar envolvidas na etiopatogênese dos corticotrofinomas. $\mathrm{Mu}$ tações no gene do CRH-R não foram encontradas em uma série de corticotrofinomas; entretanto, foi observado um aumento na expressão destes genes $(57,58)$. Este aumento poderia levar à superexpressão destes receptores; entretanto, parece mais provável que este achado apenas traduza o descontrole nos mecanismos de retroalimentação, característico destes tumores.

Um outro secretagogo do ACTH é a arginina vasopressina (AVP), que estimula as células corticotróficas através dos receptores AVP-R do tipo $V_{3}$. Alterações neste receptor também poderiam estar implicadas na tumorigênese dos corticotrofinomas. $\mathrm{Mu}$ tações no gene do AVP-R não foram encontradas em corticotrofinomas, embora tenha sido observado um aumento na expressão do gene AVP-R em alguns dos 
corticotrofinomas estudados na série de Dahia e cols. (59). Tais achados demonstram que mutações no gene do AVP-R não parecem estar envolvidas na patogênese dos corticotrofinomas, enquanto a expressão aumentada deste gene poderia explicar a resposta positiva ao teste com desmopressina (DDAVP) observada em pacientes com doença de Cushing (60).

Uma das características fundamentais dos corticotrofinomas é a sua resistência parcial à ação inibitória normalmente exercida pelos GCs, como classicamente demonstrado pela incapacidade relativa da dexametasona em suprimir sua produção de ACTH (61). Esta redução tecido-específica da sensibilidade aos GCs, encontrada nos corticotrofinomas, pode ser considerada um estado de resistência "central" aos GCs, caracterizada por uma regulação alterada do mecanismo de retro-alimentação negativa do cortisol sobre a célula corticotrófica tumoral, levando a uma ausência de inibição da secreção de ACTH pelos adenomas hipofisários e por tumores ectópicos secretores de ACTH. Os GCs exercem sua função através da ligação ao seu receptor (GR), portanto, alterações no GR poderiam explicar a resistência aos GCs encontradas nos corticotrofinomas. Em concordância com esta possibilidade, foram descritas mutações somáticas no gene do GR em tumores ectópicos secretores de ACTH (62), em um caso de síndrome de Nelson (17) e em um paciente que apresentava história pregressa de resistência generalizada aos GCs e desenvolveu, posteriormente, doença de Cushing (63). Tais achados indicaram, claramente, que anormalidades estruturais do GR poderiam contribuir para a etiopatogênese de tumores produtores de ACTH. Posteriormente, dois estudos investigaram o gene do GR em séries de corticotrofinomas, não encontrando mutações $(64,65)$; entretanto, ambos utilizaram métodos de screening (SSCP). Recentemente, estudamos toda a região codificadora e as regiões de transição intron/exon do gene GR, em 18 corticotrofinomas, não encontrando nenhuma mutação $(66,67)$. Nossos achados indicam claramente que mutações na região codificadora e nas regiões de transição intron-exon do gene do GR não estão envolvidas na etiopatogênese da doença de Cushing. É possível que alterações na região promotora do gene do GR possam estar presentes.

Uma outra explicação para a relativa resistência tecido-específica dos corticotrofinomas aos GCs poderia ser uma alteração na expressão das duas isoformas ( $\alpha$ e $\beta$ ) do GR, como já é bem caracterizada em outras situações de resistência tecido-específica aos GC, como asma $(68,69)$, artrite reumatóide $(70,71)$ e leucemia linfóide aguda $(72,73)$. Entretanto, estudando uma série de 17 corticotrofinomas, Dahia e cols. (64) não encontraram alterações na expressão das isoformas $\alpha \mathrm{e}$ $\beta$, no tecido adenomatoso, quando comparado com tecido hipofisário normal; dados similares foram encontrados por Castro e cols. (74). Apesar de não terem sido encontradas alterações significativas na expressão das 2 isoformas, a maioria dos tecidos tumorais apresentava uma expressão similar ou aumentada do GR em relação ao tecido normal, demonstrando a inexistência de down regulation do GR no tecido tumoral, a despeito da exposição crônica a concentrações elevadas de glicocorticóides (64).

A sensibilidade aos glicocorticóides é variável entre indivíduos normais (75). Os mecanismos moleculares envolvidos nestas diferenças não estão completamente estabelecidos; entretanto, a presença de determinados polimorfismos do gene do GR parece alterar a resposta aos $\operatorname{Gcs}(76,77)$. O polimorfismo no codon 363 consiste na substituição de uma asparagina por uma serina (N363S), estando associado a uma maior sensibilidade aos GCs e provavelmente a um risco cardiovascular aumentado (77,78). Estes polimorfismos têm sido descritos em corticotrofinomas e poderiam conferir vantagem seletiva no crescimento tumoral $(65,67)$. Em nossa série de corticotrofinomas (67), encontramos alguns polimorfismos no gene do GR (figura 4) em freqüências diferentes das encontradas previamente em um estudo populacional (79) e em corticotrofinomas (65), ambos realizados na Holanda. Entretanto, não encontramos associação destes polimorfismos com comportamento fenotípico específico dos tumores (67). LOH no locus do gene do GR tem sido encontrada em alguns corticotrofinomas, indicando rearranjo

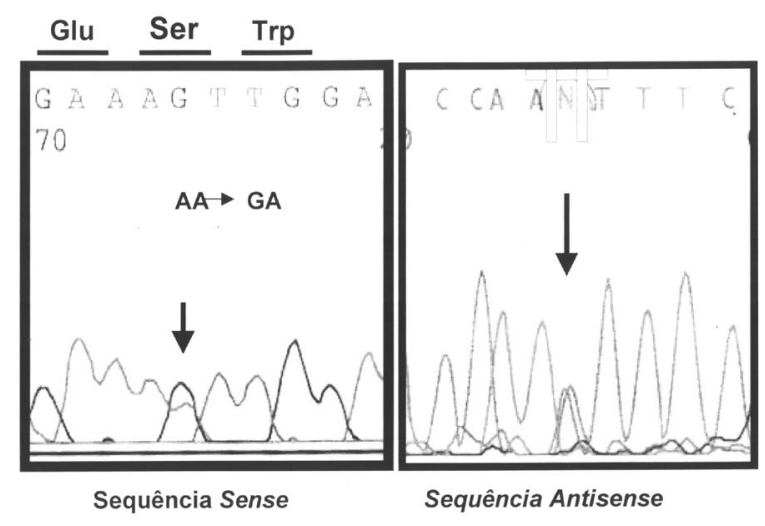

Figura 4. Polimorfismo no gene do GR encontrado em corticotrofinomas; AAT $\rightarrow$ AGT em heterozigose no codon 363 , levando à substituição do aminoácido asparagina por serina (Adaptado de Antonini e cols, 2002).

Arq Bras Endocrinol Metab vol 46 n 4 Agosto 2002 
genômico durante o início da formação tumoral. É possível que este evento contribua com a resistência aos GCs e/ou na patogênese dos corticotrofinomas (65). Apesar dos corticotrofinomas não apresentarem mutações no gene do GR, ou alteração na expressão de suas isoformas, é possível que mutações em regiões regulatórias deste gene (mutações em cis), ou ainda, alterações nos seus fatores de transcrição (mutações em trans), como, por exemplo, em proteínas co-ativadoras ou co-repressoras possam levar a resistência tecido-específica aos GCs, característica dos adenomas secretores de ACTH.

Outros membros da superfamília dos receptores nucleares, como os receptores órfãos Nur77 (NGFB-1) e Nurrl, possuem papel importante na regulação do eixo hipotálamo-hipófise-adrenal, estando envolvidos na secreção de CRH-ACTH, bem como na resposta adrenal ao ACTH (80). Nos corticotrofos, Nur77 intermedia a expressão da POMC em resposta ao estímulo do $\mathrm{CRH}$, atuando em trans na região promotora do gene da POMC, possivelmente ocupando os sítios de resposta negativa aos GCs (nGRE) $(81,82)$. O possível papel de alterações do fator de transcrição Nur77, bem como de Nurrl, no processo de formação dos corticotrofinomas ainda não foi devidamente explorado.

\section{APOPTOSE}

A maioria dos tumores hipofisários é classificada como benigna, pois não origina metástases à distância e o índice de atividade mitótica, de maneira geral, é baixo. Entretanto, quase a metade desses tumores apresenta indícios histológicos de agressividade, como invasão local. (12). Avaliando o fenômeno de apoptose nestes tumores, Green e cols. (83) relataram um índice apoptótico geral maior em tumores funcionantes, não existindo correlação com a expressão do gene p53. Kontogeorgos e cols. (84), usando outra técnica, confirmou a presença de uma maior índice apoptótico nos tumores funcionantes, mas encontrou uma associação entre o acúmulo da proteína p53 intra-nuclear e um menor grau de apoptose. Kulig e cols. (85) encontraram um índice baixo de apoptose em tumores hipofisários, exceto nos carcinomas, e demonstraram uma associação positiva entre a expressão do gene $B C L-X$ e apoptose. Tais dados podem reforçar a hipótese de que alterações em genes reguladores da apoptose podem ter algum papel no desenvolvimento dos tumores hipofisários.

\section{METILAÇÃO}

O fenômeno de metilação, juntamente com alterações no padrão de acetilação de histonas, constitui-se num dos principais mecanismos reguladores da expressão gênica $(86,87)$. De modo geral, quanto maior for o estado de metilação das ilhas $\mathrm{CpG}$ nas regiões regulatórias de um gene, menor é sua expressão (88). Alterações no padrão de metilação podem estar envolvidas no processo de formação de tumoral (89); por exemplo, a hipermetilação de genes de supressão tumoral leva a uma menor expressão destes genes e conseqüente perda de função, como no câncer de mama, onde está bem demonstrada a hipermetilação do gene $B R C A I$ (90), enquanto que hipometilação de oncogenes leva a uma maior expressão, com conseqüente ganho de função (91). Alterações no padrão de metilação de alguns genes têm sido descritas em tumores hipofisários, como no caso do gene pl6 (43). Recentemente verificou-se, in vitro, que a metilação da região promotora do gene $P O M C$ leva à perda de sua atividade. Em tumores que apresentam secreção ectópica de $\mathrm{ACTH}$, a região promotora do gene $P O M C$ está especificamente não-metilada, sugerindo que a regulação da metilação deste gene pode estar relacionada ao processo de tumorigênese, conferindo possível vantagem seletiva no crescimento do clone tumoral (92). Futuros estudos sobre o papel da metilação do gene $P O M C$, e de outros genes envolvidos na regulação das células corticotróficas, poderão contribuir no entendimento da etiopatogênese dos tumores corticotróficos.

\section{CONCLUSÕES}

Embora inúmeros avanços na compreensão dos eventos moleculares envolvidos no desenvolvimento normal e patológico da hipófise anterior tenham sido feitos, principalmente na última década, certamente ainda existem inúmeras lacunas a serem preenchidas. A aplicação dos princípios gerais de tumorigênese é adequada à tumorigênese corticotrófica e este é um processo que envolve várias etapas, resultantes da interação de eventos iniciadores e subseqüentemente, de fatores promotores, sendo, portanto, de etiologia multifatorial. De modo geral, oncogenes e genes de supressão tumoral normalmente relacionados a outros tipos de tumores não parecem contribuir neste processo, embora mutações ou alteração na expressão de alguns destes genes, como PTTG, p53 e pl6 possam estar relacionadas a um comportamento fenotípico 
mais agressivo. A investigação das vias regulatórias dos corticotrofos, principalmente a estrutura e a expressão dos genes dos receptores do CRH, AVP e GR, também não evidenciou a presença de mutações. Entretanto, é possível que alterações em fatores que regulam estes genes possam estar presentes.

Espera-se que nos próximos anos a compreensão da regulação da célula corticotrófica normal e tumoral avance significativamente, e que este conhecimento possa influenciar o manejo da doença de Cushing, seja na definição de marcadores prognósticos ou, ainda, no desenvolvimento de novas modalidades de tratamento, como a terapia gênica.

\section{REFERÊNCIAS}

1. Orth D, Kovacs WJ, Debold CR. The Adrenal Cortex. In: Wilson JD, Foster DW, eds. Williams textbook of endocrinology. 8th ed. Philadelphia;WB Saunders, 1992;489-619.

2. Herman V, Fagin J, Gonsky R, Kovacs K, Melmed S. Clonal origin of pituitary adenomas. J Clin Endocrinol Metab 1990;71:1427-33.

3. Watkins-Chow DE, Camper SA. How many homeobox genes does it take to make a pituitary gland? Trends Genet 1998; 14:284-90.

4. Dattani MT, Martinez-Barbera JP, Thomas $P Q$, Brickman JM, Gupta R, Martensson IL, et al. Mutations in the homeobox gene HESX1/Hesx 1 associated with septooptic dysplasia in human and mouse. Nat Genet 1998; Jun 19:125-33

5. Lamonerie T, Tremblay JJ, Lanctot C, Therrien M, Gauthier Y, Drouin J. Ptxl, a bicoid-related homeobox transcription factor involved in transcription of the pro-opiomelanocortin gene. Genes Dev 1996; 10:1284-95.

6. Rhodes SJ, DiMattia GE, Rosenfeld MG. Transcriptional mechanisms in anterior pituitary cell differentiation. Curr Opin Genet Dev 1994;4:709-17.

7. Sheng $H Z$, Zhadanov $A B$, Mosinger Jr B, Fujii T, Bertuzzi $S$, Grinberg $A$, et al. Specification of pituitary cell lineages by the LIM homeobox gene Lhx3. Science 1996;272:1004-7.

8. Agarwal $G$, Bhatia V, Cook S, Thomas PQ. Adrenocorticotropin deficiency in combined pituitary hormone deficiency patients homozygous for a novel PROP1 deletion. J Clin Endocrinol Metab 2000;Dec 85(12):4556-61.

9. Akita S, Webster J, Ren SG, Takino H, Said J, Zand O, et al. Human and murine pituitary expression of leukemia inhibitory factor. Novel intrapituitary regulation of adrenocorticotropin hormone synthesis and secretion. $\mathbf{J}$ Clin Invest 1995;95:1288-98.

10. Lamolet B, Pulichino AM, Lamonerie T, Gauthier Y, Brue $T$, Enjalbert $A$, et al. A pituitary cell-restricted T box factor, Tpit, activates POMC transcription in cooperation with Pitx homeoproteins. Cell 2001;Mar 23 104(6):849-59.

11. Faglia $G$, Spada A. Genesis of pituitary adenomas; state of the art. J Neurooncol 2001:Sep,54(2):95-110.
12. Sautner D, Saeger W. Invasiveness of pituitary adenomas. Pathol Res Pract 1991;187:632-6.

13. Faglia $G$. Epidemiology and pathogenesis of pituitary adenomas. Acta Endocrinol 1993; 129 (suppl. 1): 1-5.

14. Heaney AP, Horwitz GA, Wang Z, Singson R, Melmed S. Early involvement of estrogen-induced pituitary tumor transforming gene and fibroblast growth factor expression in prolactinoma pathogenesis. Nat Med 1999; 5:1317-21.

15. Ambrosi B, Faglia $G$. Epidemiology of pituitary tumors. Excerpta Medica Int Congr Ser 1991;961:159-8.

16. Landolt AM, Shibata T, Kleihues P, Tuncdogan E. Proliferation of human pituitary adenomas; Facts and speculation. Adv Biosci 1993:69:53-62.

17. Karl M, Lamberts SW, Koper JW, Katz DA, Huizenga NE, Kino T, et al. Cushing disease preceded by generalized glucocorticoid resistance; clinical consequences of a novel, dominant-negative glucocorticoid-receptor mutation. Proc Assoc Am Physicians 1995; 108:296-307.

18. Schulte HM, Oldfield EH, Allolio B, Katz DA, Berkman RA, Ali IU. Clonal composition of pituitary adenomas in patients with Cushing's disease; determination by $X$ chromosome inactivation analysis. J Clin Endocrinol Metab 1991;Dec, 73(6):1302-8.

19. Alexander JM, Biller BM, Bikkal H, Zervas NT, Arnold A Klibanski A. Clinically nonfunctioning pituitary tumors are monoclonal in origin. J Clin Invest 1990;86(1):336-40.

20. Shimon I, Melmed S. Pituitary tumor pathogenesis. J Clin Endocrinol Metab 1997:82:1675-81.

21. Williamson EA, Ince PG, Harrison D, Kendall-Taylor P, Harris $\mathrm{PE}$. G-protein mutations in human pituitary adrenocorticotrophic hormone-secreting adenomas. Eur J Clin Invest 1995;25:128-31.

22. Vallar L, Spada A, Giannattasio G. Altered Gs and adenylate cyclase activity in human $\mathrm{GH}$-secreting pituitary adenomas. Nature 1987;330:566-8.

23. Landis CA, Masters SB, Spada M, Pace AM, Bourne HR, Vallar L. GTPase inhibiting mutations activate the achain of Gs and stimulate adenylciclase in human pituitary tumors. Nature 1989:340:692-6.

24. Karga HJ, Alexander JM, Hedllley-Whyte ET, Klibanski A, Jamerson JL. Ras mutation in human pituitary tumors. J Clin Endocrinol Metab 1993;74:914-9.

25. Álvaro V, Levy L, Dubray C, Roche A, Peillon F, Querat B, et al. Invasive human pituitary tumors express a pointmutated alpha-protein kinase-C. J Clin Endocrinol Metab 1993;77:1125-9.

26. Pei L, Melmed S, Scheithauer B, Kovacs K, Benedict WF, Prager D. Frequent loss of heterozygosity at the retinoblastoma susceptibility gene (RB) locus in aggressive pituitary tumors; evidence for a chromosome 13 tumor suppressor gene other than RB. Cancer Res 1995;55:1613-6.

27. Ezzat S, Smyth HS, Ramyar L, Asa SL. Heterogenous in vivo and in vitro expression of basic fibroblast growth factor by human pituitary adenomas. J Clin Endocrinol Metab 1995;80(3):878-84.

28. Pei L, Melmed S. Isolation and characterization of a pituitary tumor-specific transforming gene. Mol Endocrinol $1997 ; 11: 433-41$.

Arq Bras Endocrinol Metab vol $46 n^{\circ} 4$ Agosto 2002 
29. Zhang X, Horwitz GA, Prezant TR, Valentini A, Nakashima $M$, Bronstein MD, et al. Structure, expression, and function of human pituitary tumor-specific transforming gene (PTTG). Mol Endocrinol 1999; 13:156-66.

30. Turner HE, Nagy Z, Gatter KC, Esiri MM, Harris AL, Wass $\mathrm{JAH}$. Angiogenesis in pituitary adenomas and the normal pituitary gland. J Clin Endocrinol Metab 2000;85:1159-62.

31. Herman V, Drazin NZ, Gonsky R, Melmed S. Molecular screening of pituitary adenomas for gene mutations and rearrangements. J Clin Endocrinol Metab 1993; $77: 50-5$.

32. Pei L, Melmed S, Scheithauer B, Kovacs K, Prager D. H-ras mutations in human pituitary carcinoma metastases. J Clin Endocrinol Metab 1994;78:842-6.

33. Buckley N, Bates AS, Broome JC, Strange RC, Perrett CW, Burke CW, et al. P53 protein accumulates in Cushing's adenomas and invasive non-functional adenomas. J Clin Endocrinol Metab 1994;79:1513-6.

34. Kontogeorgos $G$, Kapranos N, Thodou E, Sambaziotis D, Tsagarakis S. Immunocytochemical accumulation of p53 in corticotroph adenomas; relationship with heat shock proteins and apoptosis. Pituitary 1999; 1(3-4):207-12.

35. Dickman S. First p53 relative may be a new tumor suppressor. Science 1997:277:1605-6.

36. Garkavtsev I, Grigorian IA, Ossovskaya VS, Chernov MV, Chumakov PM, Gudkov AV. The candidate tumor suppressor p33ING1 cooperates with p53 in cell growth control. Nature 1998:391:295-8.

37. Osada M, Ohba M, Kawahara C, Ishioka C, Kanamaru $\mathrm{R}$, Katoh $\mathrm{l}$, et al. Cloning and functional analysis of human p51, which structurally and functionally resembles p53. Nat Med 1998:4:839-43.

38. Dahia PLM, Grossman AB. The Molecular Pathogenesis of Corticotroph Tumors. Endocr Rev 1999;20(2):136-55.

39. Mccabe CJ, Gittoes NJL, Sheppard MC, Franklyn JA. Increased MEN1 expression in sporadic pituitary tumors. Clin Endocrinol 1999;50:727-33.

40. Boggild MD, Jenkinson S, Pistorello $M$, Boscaro $M$, Scanarini $\mathrm{M}$, McTernan $\mathrm{P}$, et al. Molecular genetic studies of sporadic pituitary tumors. J Clin Endocrinol Metab 1994;78:387-92.

41. Dahia PL, Aguiar RC, Honegger J, Fahlbush R, Jordan S, Lowe DG, et al. Mutation and expression analysis of the p27/kipl gene in corticotrophin-secreting tumor. Oncongene 1998; 16:69-76.

42. Woloschak M, Yu A, Post KD. Frequent inactivation of the pl6 gene in human pituitary tumors by gene methylation. Mol Carcinog 1997;19:221-4.

43. Farrell WE, Simpson DJ, Bicknell JE, Talbot AJ, Bates AS, Clayton RN. Chromosome 9p deletions in invasive and noninvasive nonfunctional pituitary adenomas; the deleted region involves markers outside of the MTS1 and MTS2 genes. Cancer Res 1997;57:2703-9.

44. Pearce SH, Trump D, Wooding C, Sheppard MN, Clayton RN, Thakker RV. Loss of heterozygosity studies at the retinoblastoma and breast cancer susceptibility (BRCA2) loci in pituitary, parathyroid, pancreatic and carcinoid tumors. Clin Endocrinol 1996;45:195-200.
45. Bates AS, Buckley N, Boggild MD, Bicknell EJ, Perrett CW, Broome JC, et al. Clinical and genetic changes in a case of a Cushing's carcinoma. Clin Endocrinol 1995;42:663-70.

46. Hanisch A, Dieterich KD, Dietzmann K, Ludecke K, Buchfelder $M$, Fahlbusch $R$, et al. Expression of members of the interleukin-6 family of cytokines and their receptors in human pituitary and pituitary adenomas. J Clin Endocrinol Metab 2000;Nov, 85(11):4411-4.

47. Asa SL, Ramyar L, Murphy PR, Li AW, Ezzat S. The endogenous fibroblast growth factor-2 antisense gene product regulates pituitary cell growth and hormone production. Mol Endocrinol 2001;15(4):589-99.

48. McAndrew J, Paterson AJ, Asa SL, McCarthy KJ, Kudlow JE. Targeting of transforming growth factor-alpha expression to pituitary lactotrophs in transgenic mice results in selective lactotroph proliferation and adenomas. Endocrinology 1995;136(10):4479-88.

49. Ishikawa $H$, Heaney AP, Yu R, Horwitz GA, Melmed S. Human pituitary tumor-transforming gene induces angiogenesis. J Clin Endocrinol Metab 2001;86(2):867-74.

50. Akita S, Malkin J, Melmed S. Disrupted murine leukemia inhibitory factor (LIF) gene attenuates adrenocorticotropic hormone (ACTH) secretion. Endocrinology 1996; 137:3140-3.

51. Yano H, Readhead C, Nakashima M, Ren SG, Melmed S. Pituitary-directed leukemia inhibitory factor transgene causes Cushing's syndrome; neuro-immune-endocrine modulation of pituitary development. Mol Endocrinol $1998 ; 12: 1708-20$.

52. Rivier C, Brownstein M, Spiess J, Rivier J, Vale W. In vivo corticotropin-releasing factor-induced secretion of adrenocorticotropin, beta-endorphin, and corticosterone. Endocrinology 1982; 110:272-8.

53. Roberts JL, Budarf ML, Baxter JD, Herbert E. Selective reduction of proadrenocorticotropin/endorphin proteins and messenger ribonucleic acid activity in mouse pituitary tumor cells by glucocorticoids. Biochemistry 1989; 18:4907-15.

54. Drouin J, Trifiro MA, Plante RA, Nemer M, Eriksson P, Wrange $O$. Glucocorticoid receptor binding to a specific DNA sequence is required for hormone-dependent repression of pro-opiomelanocortin gene transcription. Mol Cell Biol 1989;9:5305-14.

55. Monig H, Ali IU, Oldfield EH, Schulte HM. Structure of the POMC promoter region in pituitary and extra pituitary ACTH producing tumor. Exp Clin Endocrinol 1993; 101:36-8.

56. Dieterich D, Gundelfinger ED, Lüdecke DK, Lehnert H. Mutation and expression analysis of corticotrophinreleasing factor 1 receptor in adrenocorticotrophinsecreting pituitary adenomas. J Clin Endocrinol Metab 1998;83:3327-31.

57. Castro M, Bamberger C, Tsigos C, Webster E, Moreira $A C$, Wong $M L$, et al. Normal $\mathrm{mRNA}$ and protein expression of the glucocorticoid receptor B-isoform in $\mathrm{ACTH}$ producing pituitary tumors. 80th Annual Meeting of the Endocrine Society 1998, New Orleans, USA; 2409:336 (Abstract).

58. Dahia PLM, Ahmed-Shuaib A, Jacobs RA, Chew SL, Honegger J, Fahlbush R, et al. Vasopressin receptor expres- 
sion and mutation analysis in corticotrophin-secreting tumor. J Clin Endocrinol Metab 1998;81:1768-71.

59. Malerbi DA, Mendonça BB, Liberman B, Toledo SP, Corradini $\mathrm{MC}$, et al. The desmopressin stimulation test in the differential diagnosis of Cushing's disease. Clin Endocrinol 1993;38:463-72.

60. Orth DN. Cushing's syndrome. N Engl J Med 1995;332:791-803.

61. Gaitan D, Debold R, Turney MK, Zhou P, Orth D, Kovacks WJ. Glucocorticoid receptor structure and function in an adrenocorticotropin-secreting small cell lung cancer. Mol Endocrinol 1995;9:1 193-201.

62. Karl M, Von Wichert G, Kempter E, Katz DA, Reincke M, Monig $\mathrm{H}$, et al. Nelson's syndrome associated with a somatic frame shift mutation in the glucocorticoid receptor gene. J Clin Endocrinol Metab 1996;81(1):124-9.

63. Dahia PLM, Honegger J, Reincke $M$, et al. Expression of glucocorticoid receptor isoforms in corticotrophinsecreting tumor. J Clin Endocrinol Metab 1997;82:108893.

64. Huizenga NA, de Lange P, Koper JW, Clayton RN, Farrell WE, van der Lely AJ, et al. Human adrenocorticotropinsecreting pituitary adenomas show frequent loss of heterozigosity at the glucocorticoid receptor locus. J Clin Endocrinol Metab 1998;83:917-21.

65. Antonini SR, Latronico AC, Elias LL, Liberman B, Mendonça BB, Moreira AC, et al. Glucocorticoid receptor gene structure in ACTH-secreting pituitary tumors. Endocrine Society's 82nd Annual Meeting 2000 - Toronto, Canada; 463 (abstract).

66. Antonini SR, Latronico AC, Elias LL, Liberman B, Mendonça BB, Moreira AC, et al. Glucocorticoid receptor gene olymorphisms in ACTH-secreting pituitary tumors. Clin Endocrinol 2002 (no prelo).

67. Leung DY, Martin RJ, Szefler SJ, Sher ER, Ying S, Kay AB, et al. Dysregulation of interleukin 4, interleukin 5, and interferon gamma gene expression in steroid-resistant asthma. J Exp Med 1995; 181:33-40.

68. Castro M, Leung DY, Karl M, Elliot S, Szefler SJ, Kino T, et al. Changes in the alternative splicing of the glucocorticoid receptor gene might contribute to the pathogenesis of steroid-resistant asthma. 10th International Congress of Endocrinology 1996, San Francisco, USA (abstract).

69. Kam JC, Szefler SJ, Surs W, Sher ER, Leung DY. Combination IL-2 and IL-4 reduces glucocorticoid receptor-binding affinity and $T$ cell response to glucocorticoids. J Immunol 1995; 151:3460-6.

70. Sher ER, Leung DY, Surs W, Kam JC, Zieg G, Kamada AK, et al. Steroid-resistant asthma. Cellular mechanisms contributing to inadequate response to glucocorticoid therapy. J Clin Invest 1994;93:33-9.

71. Strasser-Wozak EM, Hattmannstorfer R, Hala M, Hartmann BL, Fiegl M, Geley S, et al. Splice site mutation in the glucocorticoid receptor gene causes resistance to glucocorticoid-induced apoptosis in a human acute leukemic cell line. Cancer Res 1995:55:348-53.

72. Longui CA, Vottero A, Adamson PC, Cole DE, Kino T, Monte $\mathrm{O}$, et al. Low glucocorticoid receptor alpha/ beta ratio in T-cell lymphoblastic leukemia. Horm Metab Res 2000:32:401-6.
73. Castro $M$, Bamberger $C$, Wong $M$, Tsigos $C$, Moreira AC, Chrousos GP. The potential role of glucocorticoid receptor (gr) gene isoforms, corticotopin-releasing hormone receptor (CRH-R) and corticotropin- releasing hormone binding protein (CRHBP) genes in human pituitary tumorigenesis. Arq Bras Endocrinol Metab 1998; 42/5 (sup. 1):S283.

74. Bamberger CM, Schulte HM, Chrousos GP. Molecular determinants of glucocorticoid receptor function and tissue sensitivity to glucocorticoids. Endocr Rev 1996; 17:245-61.

75. Huizenga NA, Koper JW, De Lange P, Pols HA, Stolk RP, Burger $\mathrm{H}$, et al. A polymorphism in the glucocorticoid receptor gene may be associated with an increased sensitivity to glucocorticoids in vivo. J Clin Endocrinol Metab 1998;83:144-51

76. Lin RCY, Wang WYS, Morris BJ. High penetrance, overweight, and glucocorticoid receptor variant; case-control study. BMJ 1999;319:1337-8.

77. Lin RCY, Daziel B, Heilbrom L. High penetrant glucocorticoid receptor variant Asn363ser confers obesity and diabetes. $11^{\text {th }}$ International Congress of Endocrinology 2000; Sydney, Australia; 100 (abstract).

78. Koper JW, Stolk RP, De Lange P, Huizenga NAT, Molijn GJ, Polls HA, et al. Lack of association between five polymorphisms in the human glucocorticoid receptor gene and glucocorticoid resistance. Human Genet 1997;99:663-8.

79. Davis IJ, Lau LF. Endocrine and neurogenic regulation of the orphan nuclear receptors Nur77 and Nurr-1 in the adrenal glands. Mol Cel Biol 1994;14:3469-83.

80. Okabe T, Takayanagi R, Adachi M, Imasaki K, Nawata H. Nur77, a member of the steroid receptor subfamily, antagonizes negative feedback of ACTH synthesis and secretion by glucocorticoid in pituitary corticotrope cells. J Endocrinol 1998;156:169-75.

81. Drouin J, Maira M, Philips A. Novel mechanism of action for Nur77 and antagonism by glucocorticoids; a convergent mechanism for $\mathrm{CRH}$ activation and glucocorticoid repression of POMC gene transcription. J Steroid Biochem Mol Biol 1998;65:59-63.

82. Green VL, White MC, Hipkin LJ, Jeffreys RV, Foy PM, Atkin SL. Apoptosis and p53 suppressor gene protein expression in human anterior pituitary adenomas. Eur $\mathbf{J}$ Endocrinol 1997; 136(4):382-7.

83. Kontogeorgos $G$, Sambaziotis $D$, Piaditis $G$, Karameris $A$. Apoptosis in human pituitary adenomas; a morphologic and in situ end-labeling study. Mod Pathol 1997; 10(9):921-6.

84. Kulig E, Jin L, Qian X, Horvath E, Kovacs K, Stefaneanu L, et al. Apoptosis in nontumorous and neoplastic human pituitaries; expression of the Bcl-2 family of proteins. Am J Pathol 1999; 154(3):767-74.

85. Feinberg AP, Volgestein B. Hypomethylation of ras oncogenes in primary human cancers. Biochem Byophys Res Commun 1983;111:47-54.

86. Razin A. CpG methylation, chromatin structure and gene silencing-a three-way connection. EMBO J 1998; 17(17):4905-8.

Arq Bras Endocrinol Metab vol $46 n^{\circ} 4$ Agosto 2002 
87. Baylin SB, Makos M, Wu JJ, Yen RW, de Bustros A, Vertino $\mathrm{P}$, et al. Abnormal patterns of methylation in human neoplasia: potential consequences for tumor progression. Cancer Cells 1991;383-90.

88. Issa JP, Ottaviano YL, Celano P, Hamilton SR, Davidson $\mathrm{NE}$, Baylin SB. Methylation of the oestrogen receptor $\mathrm{CPG}$ island links ageing and neoplasia in human colon. Nat Genet 1994;Aug, 7(4):536-40.

89. Rice JC, Massey-Brown KS, Futscher BW. Aberrant methylation of the BRCAl CPG island promoter is associated with decreased BRCA1 mRNA in sporadic breast cancer cells. Oncogene 1998;17(14):1807-12.

90. Robertson KD, Jones PA. DNA methylation; past, present and future directions. Carcinogenesis 2000;21(3):461-7.
91. Newell-Price J, King P, Clark AJ. The CpG island promoter of the human proopiomelanocortin gene is methylated in nonexpressing normal tissue and tumors and represses expression. Mol Endocrinol 2001;15(2):338-48

\section{Endereço para correspondência:}

Sonir R. Antonin

Laboratoire de Pathophysiologie Endocrinienne

Hôtel-Dieu, CHUM, Université de Montréal

3850 rue Saint-Urbain, Montreal, QC, H2W 1T8, Canada 